\title{
DE LA OPRESIÓN AL RECONOCIMIENTO: REFLEXIONES DESDE LA DISCAPACIDAD
}

\author{
FROM OPPRESSION TO RECOGNITION.REFLECTIONS FROM DISABILITY
}

\section{Aleida Fernández Moreno'. María Angélica Acosta².}

\begin{abstract}
Resumen
En este artículo se analiza a la discapacidad como forma de opresión. Se inicia con un rastreo de los orígenes de la Opresión en clave de discapacidad, con Barnes (1998), para quien la opresión cultural de las "personas con insuficiencias" se puede remontar hasta el mismo nacimiento de la sociedad occidental con el ideal de "cuerpo capacitado".

En el apartado de Opresión y exclusión, se retoma el Informe Mundial de Discapacidad (Organización Mundial de la Salud y Banco Mundial, 2011), donde se reporta que estas personas "se ven obligadas a depender de otras y quedan aisladas de las oportunidades sociales, culturales y políticas generales". Continúa con la Conceptualización de la opresión en Young, quien la enuncia como un concepto plural con cinco categorías: explotación, marginación, carencia de poder, imperialismo cultural y violencia. Luego, en los movimientos sociales de los años '60 y'70 se muestra una lucha para romper las ataduras que las ligan a situaciones de opresión y exclusión y posteriormente se retoma la Convención Internacional sobre los Derechos Humanos de las personas con discapacidad (Naciones Unidas, 2006), que garantiza que los Estados Partes que la han ratificado, fomenten y protejan los derechos de las personas con discapacidad, y por esta vía se plantea el cierre del artículo con la búsqueda de la Justicia Social, en clave de reconocimiento.
\end{abstract}

\section{Palabras clave:}

Opresión- Young -(discapacidad) -movimiento social - Convención - reconocimiento.

\begin{abstract}
:
In this article we analyze disability as a form of oppression. The article begins with a trace the origins of key disability tightness with Barnes (1998), for whom the cultural oppression of the "people with impairments"3 can be traced back to the very birth of Western society to the ideal of "able-bodied".

In point of Oppression and Exclusion, World Disability Report (WHO \& WB, 2011) was taken, these people "are forced to depend on others and are isolated from the general social, cultural and political opportunities" (p. 298). Continues with the conceptualization of oppression in Young, who states oppression as a plural concept with five categories: exploitation, marginalization, powerlessness, cultural imperialism and violence.

Then in the social movements of the 60s and 70s shows a struggle to break the bonds that link them to situations of oppression and exclusion and subsequently the International Convention on the Human Rights of Persons with Disabilities (UN, 2006) was taken, ensuring that States Parties which have ratified, promote and protect the rights of PWDs, and by this means the end of the article with the quest for Social Justice, the key to recognition is proposed.
\end{abstract}

\section{Key-word:}

Oppression- Young - (disability) - social movement-Convention - recognition.

1 Terapeuta Ocupacional. Magistra en desarrollo educativo y social. Doctora en Ciencias Sociales. Coordinadora Grupo de Investigación en Discapacidad Inclusión y Sociedad de la Universidad Nacional. Universidad Nacional, Bogotá. Correo electrónico: cafernandezm@unal.edu.co

2 Fonoaudióloga. Candidata a Magister en discapacidad e inclusión social. Miembro del grupo de Grupo de Investigación en Discapacidad Inclusión y Sociedad de la Universidad Nacional. Correo electrónico: maaacostame@unal.edu.co

3 En este capítulo se emplearán las expresiones originales entre "comillas" que usaron los autores en sus textos para referirse al tema de la discapacidad, lo que da cuenta de un término históricamente situado. 


\section{INTRODUCCIÓN}

Además de los resultados que reporta Informe Mundial de Discapacidad de la Organización Mundial de la Salud y Banco Mundial (En adelante Informe Mundial, OMS y BM, 2011), este artículo retoma una investigación doctoral desarrollada en Colombiapor Fernández (2011) ${ }^{4}$, quien encuentra a partir de relatos jóvenes con discapacidad, que la sociedad en su conjunto excluye y margina a este colectivo de personas.

Posteriormente, ,se plantea la ruta que se sigue desde los movimientos sociales a la Convención Internacional sobre los Derechos Humanos de las Personas con Discapacidad (En adelante Convención ,ONU, 2006), teniendo en cuenta entre otros: los movimientos sociales de los años '60 y '70, que originaron las luchas por el reconocimiento de los derechos humanos, todo ello exigió que finalmente se promulgara la Convención en el 2006, para garantizar que los Estados Partes que la han ratificado, como en el caso de Colombia, fomenten y protejan los derechos de las personas con discapacidad.

Se continuacon una breve aproximación a la perspectiva de la teoría del reconocimiento como opción ética y política orientada a un nuevo orden social y a una justicia social para todos y todas.

Se finaliza con la discusión.

\section{Los orígenes de la Opresión en clave de discapacidad}

Para Barnes (1998), la opresión cultural se basa desde el principio de los tiempos en el ideal de "cuerpo capacitado" que influencia todas las civilizaciones occidentales sucesivas. Las personas con insuficiencias eran sacrificadas por ser

4 Este capítulo se nutre de la investigación biográfica narrativa de Aleida Fernández Moreno (2011) denominada: "Jóvenes con discapacidades: sujetos de reconocimiento". Doctorado en Ciencias Sociales. Niñez y Juventud, Cinde y la Universidad de Manizales, 2011. consideradas "débiles", "imperfectas" o "lisiadas", particularmente en Grecia las abandonaban a su suerte y en Roma las arrojaban al río Tíber. Durante la Edad Media eran también objeto de diversión y ridículo, plantea este autor retomando a Hunt; señala además, que en general estas personas son consideradas "inútiles" ya que no son capaces de contribuir al "bien económico de la comunidad". De este modo se las clasifica de "grupo minoritario" en condiciones parecidas a las de otros grupos oprimidos como los negros o los homosexuales, porque al igual que a ellos se les ve como "anormales" y "diferentes". Según Barnes, a diferencia de los teóricos estadounidenses, los ingleses aportan claridad en que la base de la opresión de los "discapacitados" está en los cambios materiales e ideológicos o culturales que acompañaron el surgimiento de la sociedad capitalista.

Por su parte Abberley (2008), plantea desde Inglaterra que una característica fundamental de la opresión es su especificidad, tanto en la forma, como en el contenido y ubicación, de allí que analizar la opresión de las personas con discapacidad implica, señalar las diferencias esenciales entre sus vidas y los que pertenecen a otros grupos de oprimidos. En relación a la diferencia biológica de los cuerpos de las personas con discapacidad, ésta forma parte de la opresión y es también consecuencia de las prácticas sociales. De acuerdo con este autor, el cuerpo es el lugar de la opresión, tanto en forma como en lo que se hace con él. Según Abberley, afirmar que las personas con discapacidad están oprimidas implica considerar una serie de aspectos, a saber:

1) las estas personas se encuentran en una posición inferior a la de otros sujetos de la sociedad, simplemente por tener discapacidad. En este sentido, las personas con discapacidad en Latinoamérica se encuentran entre los excluidos. Para Samaniego (2006) esto se traduce en pobreza y esta pobreza, en lo que constituye un círculo vicioso, aumenta la discapacidad por cuanto incrementa la vulnerabilidad de las personas ante problemas como la desnu- 
trición, las enfermedades y las condiciones de vida y trabajo poco seguras.

2) esas desventajas están relacionadas de manera dialéctica con una ideología o grupo de ideologías que justifican y perpetúan esta situación. .Hay clara vinculación de la opresión de las personas con discapacidad con dispositivos ideológicos que genera, por ejemplo, el confinamiento alimentado por el prejuicio social y la discriminación, que generó estigmatización de la población por ejemplo, tal como lo reportan los estudios de Goffman y Edgerton citados por Gerber (2008).

3) dichas desventajas y las ideologías que las sostienen no son ni naturales ni inevitables. Para Ferrante y Ferreira (2008), a partir del etiquetamiento del agente como poseedor de una deficiencia, se naturaliza bajo la forma de enfermedad, una relación de dominación que, muy lejos de ser natural, es un producto histórico de carácter arbitrario. Según Samaniego (2006), la desigualdad de oportunidades proviene de las barreras creadas en un contexto. Por tanto, cuando una persona con discapacidad "no puede funcionar», es efecto de la relación entre el individuo y su ambiente, no del hecho que el individuo sea o no capaz.

4) conlleva la identificación de algún "beneficiario" de esa situación. Para Samaniego (2006) la mayoría de los informes que hacen referencia a personas con discapacidad, van en términos de beneficiarios o denominaciones similares en la protección social.

Vale la pena también, ver quién lucra del rótulo y de los diagnósticos asociados de "discapacidad" y más particularmente de "enfermedad mental", con los grandes dividendos que generan estos diagnósticos y sus tratamientos, por ejemplo para la industria farmacéutica.

En síntesis, tanto Barnes como Abberley plantean que aplicar el concepto de opresión a la discapacidad se centra en la valoración del cuerpo y su perfección, y también implica el desarrollo de una teoría que interconecta las características comunes de las desventajas económicas, sociales y psicológicas con una comprensión de la base material de estas desventajas; y las ideologías que las difunden y reproducen. $Y$ es aquí donde surgen los movimientos sociales y el modelo social que fue la construcción teórica derivada de estos movimientos temas que se retomarán más adelante con Oliver (1998) como uno de sus líderes.

Con el ánimo de profundizar en la Teoría de la Opresión a continuación se presentan la opresión y la exclusión; y los postulados y categorías de opresión una autora clave en el tema: la filósofa política y feminista, Iris Marion Young (1949 $-2006)$.

\section{Opresión y exclusión}

El Informe Mundial (OMS y BM, 2011, p. 298), reporta que en todo el mundo, las personas con discapacidad tienen peores resultados sanitarios, peores resultados académicos, una menor participación económica y unas tasas de pobreza más altas que las personas sin discapacidad. De igual manera se enuncia que estas personas "se ven obligadas a depender de otras y quedan aisladas de las oportunidades sociales, culturales y políticas generales". Además, la ausencia de un empleo, por ejemplo, dificulta la adquisición de bienes materiales, lo que genera situaciones de dependencia, que a su vez afecta el ejercicio de una propia y plena ciudadanía. En consecuencia, se generan obstáculos que entorpecen el acceso de las personas con discapacidad a servicios que la mayoría considera obvios, en particular la salud, la educación, el empleo, el transporte, o la información.

Todas las situaciones señaladas en el ámbito internacional se aprecian vigentes en contextos latinoamericanos como Colombia, según lo evidenció Fernández (2011), quien encuentra por ejemplo marginaciones y exclusiones de los y 
las jóvenes con discapacidad de la educación incluso en el sector público; la inaccesibilidad al sistema de salud por factores físicos y barreras actitudinales. Registró igual precariedad en temas de diseño y funcionalidad tecnológica; en el trasporte tradicional que sigue siendo opresora y excluyente, que se constituye en una barrera más para afrontar.

Para Young (2000, p. 226), los miembros de grupos oprimidos con frecuencia experimentan esta sensación de ser evitados, de aversión, detectan expresiones de nerviosismo, condescendencia y tendencia a crear estereotipos. Para estas personas el encuentro en su totalidad, a menudo Ilena de manera dolorosa su conciencia discursiva. Tal conducta las devuelve a su identidad de grupo, haciendo que se sientan observadas, señaladas o, a la inversa, invisibles, no tomadas en serio o, aún peor, degradadas. Estas aristas se amplían a continuación.

Conceptualización de la opresión en Young

En el siglo XIX, afirma Young (2000) la mirada normalizadora de la razón científica que compara, diferencia, jerarquiza, homogeneiza, excluye y expresa una visión de la subjetividad y la objetividad que ha tenido una gran influencia y repercusión en la cultura moderna que contribuyó a legitimar la superioridad racial, sexual y nacional, marginando a las personas con discapacidad particularmente, perspectiva que sigue vigente aun hoy día.
Ser dependiente en la sociedad implica estar legítimamente sujeto a la frecuentemente arbitraria y masiva autoridad de quienes suministran los servicios sociales, y de otros administradores públicos y privados que aplican reglas que la persona marginal debe acatar, ejerciendo además poder sobre sus condiciones de vida. Así según Young (2000, p. 95-96), dado que dependen de instituciones burocráticas que les faciliten apoyo o servicios, las personas mayores, pobres o "discapacitados mentales o físicos" están sujetas a un tratamiento paternalista, punitivo, degradante $y$ arbitrario por parte de la gente y las políticas asociadas a las burocracias del bienestar.

Atendiendo a particularidades de los contextos, Young (2000), se refiere al término opresión para describir las injusticias de las que son "víctimas" los diferentes miembros de los grupos sociales minoritarios, para quienes la autora enunció la opresión como un concepto plural en el que se incluyen cinco categorías: explotación, marginación, carencia de poder, imperialismo cultural y violencia.

En la Tabla No. 1, que se presenta a continuación se describen cada una y se desarrolla cómo opera cada categoría en clave de discapacidad. Es de notar que se presenta una aproximación, pues cada tipo de discapacidad (Física, sensorial, psicosocial, entre otras) evoluciona de manera distinta según el contexto que la persona habite, las posibilidades de acceso real a derechos tales como la salud, educación, trabajo, cultura, etc.

Tabla No. 1 Categorías de Opresión en Young en correlación con situaciones de discapacidad

\begin{tabular}{|c|l|}
\hline Categoría de Opresión Young (2000) & Situación de discapacidad \\
\hline - Explotación: en la sociedad capitalista actual están & Las personas con discapacidad experimentan situacio- \\
ausentes las clases sociales institucionalizadas, sin & nes de explotación en el mercado laboral, pues des- \\
embargo existen divisiones entre los individuos que & empeñan mayormente empleos informales al servicio \\
son propietarios y los que realizan la mano de obra. & de otro y aportan la mano de obra sin remuneración \\
$\begin{array}{l}\text { De modo que la opresión proviene de un proceso } \\
\text { de transferencia de los resultados del trabajo de un } \\
\text { grupo a favor de otro. }\end{array}$ & en muchos casos. \\
\hline
\end{tabular}


- Marginación: Young entiende el término como la opresión a que son sometidos aquellos a quienes el mercado de trabajo, o no puede, o no quiere emplear. La marginación conlleva a la privación de condiciones culturales, prácticas institucionales, para el ejercicio de capacidades en un contexto de reconocimiento e interacción.

- Carencia de poder: hace alusión a la carencia de autoridad que se presenta con relación a la división social del trabajo entre profesionales y no profesionales. Los profesionales se encuentran en una situación de privilegio respecto a quienes no lo son, en virtud de su ubicación en la división del trabajo y del estatus que ella implica. Esta situación deja a las personas no profesionales con pocas oportunidades para desarrollar y usar sus capacidades.

- Imperialismo cultural: se manifiesta por la universalización de la experiencia, los valores, las creencias y la cultura del grupo dominante en la sociedad, lo que los posiciona como característicos de toda la humanidad.

- Violencia: forma de opresión caracterizada por la potencialidad y por la predisposición compartida por los miembros del grupo de ser sujetos de violencia.

Fuente: Elaboración propia a partir de los planteamientos de Young (2000);

Unicef (2008) y el Informe Mundial de Discapacidad (OMS-BM, 2011).
Según la UNICEF (2008) es menos probable que los niños y niñas con discapacidad asistan a la escuela. El Informe Mundial sobre la Discapacidad (2011), enuncia que estas personas, en edad de trabajar, registran tasas de desempleo más altas que las personas sin discapacidad, que el mercado laboral es mayormente informal, y además que un número considerable tienen empleos contingentes o de tiempo parcial. Por otra parte, hay empleadores que todavía piensan que las personas con discapacidad no están calificadas o no son productivas.

Los imaginarios sociales en relación a la capacidad de las personas con discapacidad, aleja la posibilidad de decidir sobre sus propias vidas y los ubica en una posición inferior con relación a las personas sin discapacidad, frente a lo que no pueden hacer nada. No tienen forma de llevar a cabo sus planes de vida, muchos están supeditados a decisiones de otros.

En un gran número de países como Colombia existen medidas jurídicas como la Interdicción que permite que entre otras las personas sean institucionalizadas o esterilizadas contra su voluntad por ejemplo.

En la medida que las personas con discapacidad interactúan con el otro, experimentan el predominio de imaginarios socioculturales que son en su mayoría excluyentes, que les segregan por considerarles diferente, por no acomodarse a la norma y a los preceptos de una sociedad dominante.

Según el Informe Mundial (OMS- BM 2011, p: 66), las personas con discapacidad están más expuestas al riesgo de sufrir violencia que las demás. Se ha demostrado que la prevalencia de abuso sexual contra las personas con discapacidad es mayor, sobre todo en el caso de hombres y mujeres internados con discapacidad intelectual, parejas intimas y adolescentes.
A continuación se puede ampliar los ejemplos presentados en la Tabla No. 1, considerando que:

Temas de explotación, si bien ya se señaló se asocian a empleos precarios y no remunerados, también se vinculan a situaciones extremas donde estas personas son "usadas", por otros, como mendigos; con ello se perpetúan imaginarios so- ciales estigmatizantes y la visión caritativa frente a la discapacidad.

La marginación y la carencia de poder son evidentes en la institucionalización; la Unicef en el 2013, reitera que en muchos países, las respuestas más frecuentes a la situación de los niños y niñas con discapacidad son la institucionalización, 
el abandono o el descuido, estas "respuestas" según Fernández y García (2014), son realmente el problema que se origina en nociones negativas o incluso paternalistas sobre la discapacidad, donde la dependencia y la exclusión se perpetúan a causa de la ignorancia.

En Colombia, en los relatos de vida que retoma Fernández (2011), se encuentra que el abandono y la institucionalización de personas con deficiencias graves o crónicas y de personas con discapacidades cognitivas o psicosociales, continúan vigentes como una expresión de desprecio social que afecta particularmente a este colectivo de personas. Estas prácticas a su vez producen estigmatización, tal como detallan los estudios de Goffman y Edgerton retomados por Gerber (2008).

En el imperialismo cultural, por ejemplo quien pertenece a la Ilamada "cultura Sorda", tiene una forma de reconocer modos de vida, valores, creencias y actitudes que les confieren un sello especial. Esta pertenencia a un grupo minoritario, suele propiciar connotaciones negativas, discriminación y exclusiones.

En cuanto a la violencia, la UNICEF (2008) plantea que los niños y niñas con discapacidad a menudo sufren discriminación y exclusión, y están especialmente expuestos a la violencia física, sexual y emocional y al maltrato verbal. En ese mismo sentido Fernández (2011), reporta que la Alcaldía Mayor de Bogotá (2004), plantea que el tema de seguridad y bienestar físico aún no está resuelto, pues son las niñas, niños y adolescentes con discapacidades los más vulnerables frente al abandono, el maltrato y el abuso.

Young (2000), con las categorías aquí presentadas desarrolló un análisis del concepto de opresión, teniendo en cuenta la manera como fue utilizado desde los años sesenta por los movimientos sociales de los Estados Unidos, dentro de los que se consideran grupos oprimidos de mujeres, gente negra, chicana, puertorriqueña, otras personas americanas de habla hispana, gente indígena, personas judías, lesbianas, hombres gays, gente árabe, asiática, personas ancianas, gente de clase obrera y "discapacitados" físicos y mentales. Esta autora destacó que estos grupos no son oprimidos en la misma medida, ni del mismo modo, por lo cual es difícil definir un conjunto único de criterios que describan la condición de opresión de estos colectivos. Por lo expuesto, se dedica el siguiente apartado a los movimientos sociales.

\section{De los Movimientos sociales a la Convención, claves para la justicia social}

Los movimientos sociales de los '60 y '70 surgen en el mundo anglosajón para hacer frente a la opresión que sufre el colectivo de personas con discapacidad que remite necesariamente a hablar del "Modelo social de la discapacidad", surgido de del ambiente de la academia y militancia norteamericana. Este modelo se orienta a reclamar los derechos civiles de las personas con discapacidad, comprendiéndolas como minoría oprimida. Estos aportes, incorporados en el contexto del Reino Unido, a la luz del marxismo, serían leídos en clave opresión social, referentes obligados en esta perspectiva como ya se mencionó son Mike Oliver y Colin Barnes.

En palabras de Oliver (1983), fue cuando se comenzaron a escuchar las voces de las personas con discapacidad, se identificó el modelo social de la discapacidad, el cual se convirtió en un concepto básico sobre el que los "discapacitados" empezaron a interpretar sus propias experiencias (de opresión) y a organizar su propio movimiento político, que se logra por todas las luchas gestadas por las propias personas con discapacidad y sus organizaciones, que buscan alternativas diferentes al abandono, a la institucionalización, a la esterilización forzada.

Por lo anterior, particularmente movilizadoras resultaron ser las respuestas de los colectivos de personas con discapacidad ante la institucionalización, pues según Palacios (2008) tradicionalmente ha dado lugar a un tratamiento degradante y una forma de exclusión particularmente de las niñas y niños con discapacidad en todos los ámbitos de la vida en sociedad. Para Contino (2010), 
citado por Fernández y García (2014) los condicionamientos (los que se generan por la institucionalización) tienden a producir una posición pasiva, dependiente, infantilizada y alienada en las normas disciplinares institucionales que están afianzadas, necesariamente, en políticas asistencialistas. Enfrentando las difíciles e inhumanas condiciones que produce la institucionalización, Pérez (2012) destaca la perspectiva de la antipsiquiatría comparada de la emergencia de los movimientos de usuarios y de sobrevivientes, que buscan liberarse de la medicalización y superar las traumáticas experiencias del encierro y de la lobotomía, como nuevas opciones para enfrentar la institucionalización en particular y la opresión en general.

Los movimientos sociales y el Modelo Social de Discapacidad, se configuran en su esencia una lucha por el reconocimiento de las personas con discapacidad como ciudadanos y fue la internacionalización de tales movimientos lo que confluyó en la cristalización de diversos instrumentos legales internacionales, entre los que adquiere relevancia la Convención (ONU, 2006). La misma, a fin de poner fin a la situación de opresión de las personas con discapacidad en el mundo actual, promueve que los Estados Partes que la han ratificado, como en el caso de Colombia, ${ }^{5}$ fomenten y protejan los derechos de las personas con discapacidad.

\section{Opresión Versus Reconocimiento}

La respuesta a la opresión es la justicia social, señala Young (2000 p.12). La autora enuncia que allí donde existen diferencias de grupo social y algunos grupos son privilegiados mientras son otros son oprimidos, la justicia social requiere recono-

5 Estado social de derecho que se convirtió el 10 de mayo del 2011 en el centésimo país en ratificar la Convención, inicia su compromiso mediante la aprobación de la Ley estatutaria 1618 del 27 de febrero de 2013, por medio de la cual se establecen las condiciones para garantizar el pleno ejercicio de los derechos de las personas con discapacidad. cer y atender explícitamente a esa diferencia del grupo para socavar la opresión. Justicia social significa para Young (2000, p.32) la eliminación de la dominación y la opresión institucionalizadas. Cualquier aspecto la organización y práctica social relevantes para la dominación y la opresión está, en principio, sujeto a evaluación conforme a los ideales de la justicia.

Para Samaniego (2006) la lucha de las personas con discapacidad por extender los espacios de reconocimiento y aplicación de sus derechos es latente, dado que las estadísticas aún no evidencian la visibilización de las personas con discapacidad con un enfoque holístico, en un contexto pleno en creencias, relaciones, ideologías, con principio de individualidad y sentido de pertenencia grupal. Las personas con discapacidad y sus organizaciones están trabajando estratégicamente con socios tanto nuevos como tradicionales, y están buscando vigorosamente obtener un acceso igualitario al empleo, asistencia médica, transporte, vivienda, educación, cultura y otros derechos fundamentales que son derechos humanos universales. Nussbaum (2005) afirmó que los ciudadanos que cultivan su humanidad necesitan, además, la capacidad de verse a sí mismos no sólo como ciudadanos pertenecientes a alguna región o grupo, sino también, y sobre todo, como seres vinculados a los demás seres humanos por lazos de reconocimiento y mutua preocupación.

Entonces, el reconocimiento como respuesta a la Opresión, se puede considerar siguiendo los planteamientos de Nancy Fraser ${ }^{6}$ (2006, p. 20) quien considera que el reconocimiento de la dignidad humana se torna en un principio central de justicia social. Así, el paradigma del reconocimiento se enfrenta a injusticias que interpreta como culturales, que supone enraizadas en patrones sociales de representación, interpretación y comunicación. Es en Honneth $(1997 ; 2006)$ en

6 Se aclara que la postura propia de Fraser es Bivalente, es decir la justicia social requiere de redistribución y de reconocimiento. Confróntese Fraser (2006). 
quien se encuentra una teoría crítica centrada en la Ética del reconocimiento que en tensión permanente presenta las esferas del reconocimiento y las formas de desprecio de las que se derivan las luchas por el reconocimiento y las reivindicaciones morales.

El reconocimiento en Honneth (2006), se puede ver como un proceso de configuración progresiva de la identidad, en el marco de secuenciadas y cada vez más complejas formas de interacción y socialización: en la familia, en las instituciones y en la comunidad ética más amplia, en donde tanto el "ser reconocido" como el "reconocer" son igualmente importantes, para vencer cualquier tipo de opresión. Todo ello es relevante por cuanto en la teoría del reconocimiento según Honneth (2006: p.196) se encuentra: una realidad social que se revela (teoría social) por medio de la misma concepción que debido a su contenido normativo, puede utilizarse para evaluar un cambio social (una concepción de justicia) de un modo que permita articular las perspectivas de los afectados (psicología moral).

El respeto es una categoría fundamental del reconocimiento y la dignificación de la condición de las personas con discapacidad. Para Honneth, el respeto moral designa una forma de reconocimiento que puede esperarse en igual medida de todos los sujetos; en el caso de la estimación, finalmente, le corresponden realizaciones morales que sólo en el marco de comunidades concretas poseen un carácter obligatorio y vinculante. El respeto en la dinámica intersubjetiva es un reclamo de igualdad frente a otros, que involucra el reconocimiento de la humanidad en cualquier circunstancia de vida: como criterio para evitar la discriminación, asegurar la justicia/equidad y lograr la comprensión de la diferencia. Los planteamientos de Young (2000), Kitay (2003) y Nussbaum (2007) al respecto son claves.

Según Fernández (2011) existen distintas formas de respuestas frente al desprecio y a la opresión, así las personas con discapacidad podrán superar a través de las luchas por el reconocimiento muchas de las difíciles situaciones que enfrentan.
- Protección: entre ellas aislarse; autoexcluirse; solicitar ayuda a los adultos, en especial a los maestros. Los jóvenes recordaban que en el colegio eran objeto de burlas, ofensas y que preferían por ejemplo quedarse en el aula de clase y no salir al "recreo" para no ser maltratados y humillados.

- Resistencia: ignorar a los otros, no responder de ninguna forma o defenderse de las agresiones agrediendo a su vez. Callar, no responder son formas de resistencia vigente para colectivos de personas que han sido oprimidos y despreciados.

- Reclamación de derechos: exigir verbalmente o por escrito el cumplimiento de las normas o derechos en general. En varios países como Colombia, los derechos de petición y las tutelas son mecanismos jurídicos que salvaguardan los derechos de las personas con discapacidad que cada día son más usados por las personas con discapacidad, sus familias y sus organizaciones para que le sean respetados, restituidos o reivindicados sus derechos.

Estas son algunas de las respuestas que se identificaron en los relatos de un grupo de jóvenes, pueden ser la claves para enfrentar la opresión y que llevan no solo a una lucha por el reconocimiento individual sino a luchas de colectivos sociales para la restitución y la reivindicación de sus derechos. Así, tener en cuenta la teoría del reconocimiento que considera a todas las personas como sujetos de derechos, sitúa la discusión en el terreno social y político y proyecta una nueva visión sobre las personas con discapacidad.

\section{DISCUSIÓN}

Los teóricos de la opresión como Barnes y Abberley, brindan elementos interesantes para comprender y caracterizar la actual persistencia de formas de opresión experimentadas por las per- 
sonas con discapacidad, en la sociedad global y en el caso colombiano particular, especialmente los planteamientos donde los estereotipos distorsionan de manera sistemática las identidades de los sujetos, que restringe la integridad de su humanidad al reducirlo únicamente a sus aspectos "problemáticos".

Sin embargo lo que enseña Young (2000), es que la opresión no es una condición que se pueda generalizar, pues como bien lo enunció esta autora los grupos oprimidos, la mirada normalizadora de la ciencia se fija en grupos sociales oprimidos: en los cuerpos objetivados que las mujeres, las personas negras, judías, homosexuales, ancianas, "locas o débiles mentales", así algunas personas están atrapados en sus cuerpos objetivados, ciegos, mudos y pasivos, pero es su experiencia única y subjetiva donde la opresión se materializa en distinta medida y de diferente forma. Por ello, no se puede tomar en genérico ni suponer que cualquiera de estas formas de opresión impactan de igual manera a cada persona, algunos pueden sentirse agraviados por la carencia de poder, o la explotación, otros se sentirán humillados por el imperialismo cultural, otro por la marginación, de igual manera alguna persona con discapacidad podrá afrontar con resiliencia, por ejemplo la violencia.

Así, el desprecio social producido por cualquier forma de opresión, en cualquiera de sus expresiones es considerado, en la teoría del reconocimiento, como una fuerza moral que impulsa las luchas por el reconocimiento y la reivindicación moral, este motor del cambio social brinda una nueva esperanza a los colectivos de personas con discapacidad para hacer valer sus derechos y su ciudadanía.

Así, y teniendo en cuenta en cuenta la discapacidad, tienen necesidades particulares y requieren por tanto apoyos y abordajes distintos, en este sentido se hacen necesario la generación de políticas diferenciadas tal como las propuestas por Young (2000) y en políticas de reconocimiento según los planteamientos de Honneth.

\section{REFERENCIAS BIBLIOGRÁFICAS}

Abberley, P. (2008) El concepto de opresión y el desarrollo de una teoría social de la discapacidad. En: Superar las barreras de la discapacidad. Barton, L. (Comp.). Madrid: Morata.

Barnes, C. (1998). Las teorías de la discapacidad y los orígenes de la opresión de las personas discapacitadas en la sociedad occidental. En: Discapacidad y Sociedad. Barton, L. (Comp.). Madrid: Morata.

Fernández, A. (2011). Jóvenes con discapacidades: sujetos de reconocimiento, Tesis para optar al título del Doctorado en Ciencias Sociales. Niñez y Juventud. Cinde y la Universidad de Manizales. Universidad de Manizales. Manizales. Colombia.

Fernández, A. y García, S. (2014). Reflexiones sobre el abandono e institucionalización. Una aproximación desde la Terapia Ocupacional. En cuestiones contemporáneas de la terapia ocupacional en américa del sur.

Ferrante, C y Ferreira, A.M (2008). Cuerpo, discapacidad y trayectorias sociales:Dos estudios de caso comparados. En: Revista de Antropología Experimental n 8, 2008. págs: 403-428. Disponible en: http://www.ujaen.es/huesped/rae/articulos2008/29ferrante08. pdf

Fraser N. (2006). La justicia social en la era de la política de la identidad: Redistribución, reconocimiento y participación. En: ¿Redistribución o Reconocimiento? Madrid: Morata.

Gerber, D. (2008). Escuchar a las personas con discapacidad En: Superar las barreras de la discapacidad. Barton, L. (Comp.). Madrid: Morata.

Honneth, A. (1997). La lucha por el reconocimiento. Por una gramática moral de los conflictos sociales. Barcelona: Crítica Grijalbo.

Honneth, A. (2006). Redistribución como reconocimiento: Respuesta a Nancy Fraser. En: ¿Redistribución o Reconocimiento? Madrid: Morata.

Kitay, E. (2003). Discapacidad, Dignidad y Protección. En: El debate sobre la dignidad humana. Navarra, España: Editorial Verbo Divino.

Nussbaum, M. (2005). El cultivo de la humanidad. Barcelona: Paidós.

Nussbaum, M. (2007). Las fronteras de la justicia. Barcelona: Paidós.

Organización de las Naciones Unidas - ONU. (2006). Convención Internacional de los Derechos Humanos de las Personas con Discapacidad. Disponible en: http://www.un.org/spanish/disabilities/

Organización Mundial de la Salud y Banco Mundial (2011). Informe mundial sobre la discapacidad. Malta: OMS; 2011. Disponible en: http://new.paho.org/arg/images/Gallery/Informe_spa.pdf. Consultado enero de 2013.

Oliver, M. (1983). Social Work with Disabled People. Basingstoke:Macmillan.

Oliver, M. (1998). ¿Una sociología de la discapacidad o una sociología discapacitada? En: Discapacidad y Sociedad. Barton, L. (Comp.). Madrid: Morata.

Palacios, A. (2008). El modelo social de discapacidad: orígenes, caracterización y plasmación en la convención internacional sobre los derechos de las personas con discapacidad. Madrid: CERMI. 
Pérez, C. (2012). Una nueva Antipsiquiatría. Crítica y conocimiento de las técnicas de control psiquiátrico. Ediciones LOM. Chile: Santiago de Chile.

Samaniego, P. (2006). Aproximación a la realidad de las personas con discapacidad en Latinoamérica. Madrid: CERMI.

Unicef (2008). "Estado mundial de la infancia. Conmemoración de los 20 años de la Convención sobre los derechos del niño. Nueva York: Autor.

Unicef (2013). "Estado mundial de la infancia. Niñas y niños con discapacidad". Disponible en:http://www.unicef.org/spanish/ sowc2013/

Young, I. M. (2000). La justicia y la política de la diferencia. Madrid: Cátedra 